\title{
A COCHLEAR IMPLANT ROUND WINDOW ELECTRODE ARRAY
}

\author{
BY
}

G. M. CLARK, J. F. PATRICK AND Q. BAILEY 


\title{
A cochlear implant round window electrode array
}

\author{
By G. M. Clatk, J. F. Patrick and Q. Bailey (Melbourne)
}

ONE important aspect of cochlear implantation is the placement of a multiple-electrode array close to residual auditory nerve fibres so that discrete groups of fibres can be stimulated electrically according to the place basis of frequency coding. Furthermore, in patients who are postlingually deaf these electrodes should lie in relation to the nerve fibres which are responsible for transmitting the frequencies which are important in speech comprehension, viz. $300-3,000 \mathrm{~Hz}$. The method of electrode insertion should also ensure that there is no significant damage to auditory nerve fibres.

It has been difficult for previously proposed electrode systems to meet all these requirements (Clark et al., 1977) and one development from our own laboratory has been to insert a fine electrode through an opening in the apical turn of the cochlea as this will pass around the turns of the cochlea and lie close to the auditory nerve fibres which convey speech frequencies. This particular approach, however, has two disadvantages. First, only an electrode array with a small diameter will pass satisfactorily and, secondly, as shown in a histopathological study there is loss of auditory nerve fibres underlying the opening drilled into the apical turn and there is more overall damage than with a round window electrode insertion (Clark, 1977). For this reason we have carried out studies to examine those electrode physical properties, materials and design that would permit the insertion of a multiple electrode system through the round window for a distance of $20-25 \mathrm{~mm}$. This would then allow the electrode to lie in the speech frequency areas, as von Békésy (1960) has shown that the $300 \mathrm{~Hz}$ area is about $27 \mathrm{~mm}$ from the stapes footplate.

Studies were carried out with different materials inserted into fresh human temporal bones. The length of the electrode from the round window was measured and the placement of the electrode was examined by drilling away the overlying bone. As a result, it was found that a silastic tube with an outside diameter of $0.64 \mathrm{~mm}$ was satisfactory and could be inserted, on average for $20 \mathrm{~mm}$. Steps were then taken to design the electrode array so that it would be both robust and atraumatic. The most satisfactory solution was obtained by constructing the array so that the electrodes were made of $0.3 \mathrm{~mm}$ wide rings of platinum encircling the tube and indenting the surface. These were welded to teflon-coated wires containing 90 per cent platinum and 10 per cent iridium and with a bare diameter of one thousandth of an inch (Fig. 1). The insertion characteristics of the electrode 


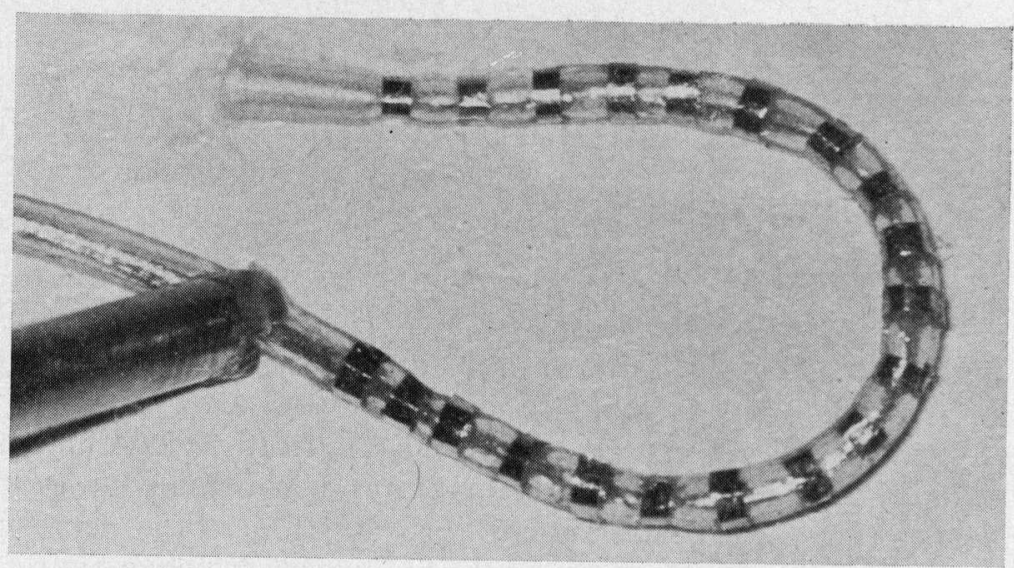

FIG. 1

A photograph of the cochlear implant electrode array which has been bent to show its flexibility. Magnification $\times 13$.

were improved by filling it with medical grade silastic. Further studies in which the dimensions of the array are varied are in progress. This should enable an array of this type to be passed further along the cochlea. An illustration of the electrode passing through the round window and around the basal to middle turns can be seen in Fig. 2 .

The electrode has been designed so that ten channels of electrical stimulation can be produced, as this has been suggested as the minimum number required for satisfactory speech comprehension, and is compatible with the receiver-stimulator unit designed in the Departments of Otolaryn-

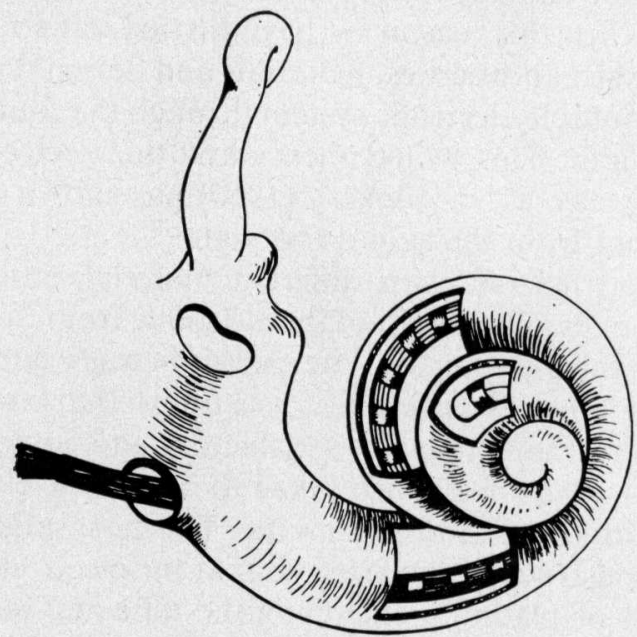

FIG. 2

A diagram showing the electrode array placed through the round window and around the turns of the cochlea. 
gology and Electrical Engineering at the University of Melbourne (UMDOLEE). It has 20 electrodes and can therefore be used for bipolar electrical stimulation, as it has been shown by Black and Clark (1977, 1978) that bipolar stimulation is effective in reducing the length constant in the cochlea. Consequently, bipolar stimulation is better than monopolar stimulation in restricting the current flow to a localized group of auditory nerve fibres. Furthermore, in order to restrict the electrodes to the speech frequency range, which occurs along a length of $15 \mathrm{~mm}$, the electrodes have been restricted to the distal $15 \mathrm{~mm}$ of the electrode. Consequently, the 20 electrodes which are $0.3 \mathrm{~mm}$ wide are separated by $0.45 \mathrm{~mm}$.

\section{Summary}

This multiple-electrode array for round window cochlear implantation is a robust, reliable system for inserting $20 \mathrm{~mm}$ along the scala tympani with a minimum of trauma and can provide for bipolar stimulation.

\section{Acknowledgement}

We would like to acknowledge the financial help from the Channel $O$ Nerve Deafness Appeal which enabled this work to be carried out. We would like to thank Mrs. S. Derham and Mr. L. Cole for technical assistance and Miss J. Maher for the typing.

\section{REFERENCES}

BÉKésY, G. von (1960) Experiments in Hearing, Chapter II, McGraw-Hill, New York.

Black, R., and Clark, G. M. (1977) Melbourne University Research Report, 140.

BlaCk, R., and Clark, G. M. (1978) Proceedings of The Australian Physiological and Pharmacological Society, 9, 71P.

CLARK, G. M. (1977) Journal of Laryngology and Otology, 91, 185.

Clark, G. M., Black, R., Dewhurst, D. J., Forster, I. C., Patrick, J. F., and Tong, Y. C. (1977) Medical Progress through Technology, 5, 127.

Department of Otolaryngology,

University of Melbourne,

32 Gisborne Street,

East Melbourne 3002,

Victoria, Australia. 


\section{University Library}

\section{- M M I E R R V A gateway to Melbourne's research publications}

Minerva Access is the Institutional Repository of The University of Melbourne

Author/s:

Clark, Graeme M.;Patrick, J. F.;Bailey, Q.

Title:

A cochlear implant round window electrode array

Date:

1979

Citation:

Clark, G. M., Patrick, J. F., \& Bailey, Q. R. (1979). A cochlear implant round window electrode array. Journal of Laryngology and Otology, February, 93(2), 107-109.

Persistent Link:

http://hdl.handle.net/11343/28717 